This is the post print version of the article, which has been published in Science and Public Policy. 2018, 45 (2), 221-231. http://dx.doi.org/10.1093/scipol/scx059

This document has been downloaded from TamPubuta.fi The Institutional Repository of University of Tampere

\title{
Triple Helix model and institutional logics in Shenzhen Special Economic Zone
}

Cui Liu

College of Civil Engineering and Architecture, Zhejiang University, 310058 China cui_liu@zju.edu.cn

Yuzhuo Cai

Higher Education Group, Faculty of Management, University of Tampere, 33014 Finland yuzhuo.cai@uta.fi

\section{Cite the paper as:}

Liu, C., \& Cai, Y. (2017 online first). Triple Helix Model and Institutional Logics in Shenzhen Special Economic Zone. Science and Public Policy, scx059-scx059. doi:10.1093/scipol/scx059

\section{Abstract}

This paper examines the features of Triple Helix model in Shenzhen Special Economic Zone and analyses the driving forces of the featured model from the institutional logics perspective. The statist-fading balanced Triple Helix model in Shenzhen is characterised by 1) the loosened control of central government and 2) the balanced interaction of local government, industry and university. The former character is closely related with the internal changes of state logics, i.e. the rescaling of state power due to decentralization, regional disparity, and global networks. The latter is driven by the structural overlap of state, market and professional logics along with the transition of China from a centrally planned economy towards a market oriented economy and the importance of innovation and learning in the knowledge society.

Key words: Special Economic Zone; Triple Helix; institutional logics; Shenzhen 


\section{Introduction}

China's economic reforms have been driven by an experiment-based approach, which has also a potential to facilitate institutional innovation (Heilmann 2008). The well-known examples of such approach are the development of special economic zones (SEZs) (Yeung et al. 2009). SEZs were established to concentrate resources in designated areas for spill-over effect, to gain new knowledge through experimental learning, to attract foreign direct investment (FDI) for export growth and employment generation, and to facilitate economic and institutional liberalisation (Wei 2000).

Existing studies have discussed widely the economic performance and innovation capability of SEZs. For instance, it has been claimed that Chinese SEZs have become hotbed of new and hightech firms and they are more competitive than other regions in acquiring technological capacity (Wei 2000); Chinese SEZs tend to cultivate an innovative and entrepreneurial culture through a strongly motivated community composed of qualified workers and a large number of immigrants seeking better jobs and new opportunities (Zeng 2010). While existing studies have commonly acknowledged the success of Chinese SEZs in fostering technological innovation and economic growth, they attribute the success of Chinese SEZs to a gradual and pragmatic approach, institutional autonomy, continued FDI, proactive government, preferential policies, location advantages and so on (Ge 1999; Shen and Kee 2017; Tantri 2012; Wei 2000; Zeng 2010). It has been found that Chinese SEZs have enabled the combination of decentralised regional experimentation and centralised state interference through incorporating successful experiences of local experiments into national policymaking (Heilmann 2008).

Whereas these studies accentuate the effectiveness and potential of SEZs in technology and institutional innovation, they haven't provided deep analysis on the features of innovation system development in SEZs. Moreover, although these studies have been aware of the role of institutions in 
promoting the innovation system development in SEZs, they pay little attention to the logics driving the institutional changes.

To fill these research gaps, this paper tries to explore the features and rationales of innovation system development in SEZs by incorporating the Triple Helix model and institutional logics perspective. Triple Helix is useful to explain the specific model of innovation system development through the dynamic interactions between university, industry and government (Etzkowitz and Leydesdorff 1995), while the institutional logics perspective provides an analytical tool to understand the influences of societal-level culture on the cognition and behaviour of individuals and organizations (Thornton et al. 2012). The combination of Triple Helix model and institutional logics perspectives also corresponds to the connotations of innovation system which consists of complex functions and interactions among various organisations and institutions (Edquist 1997; Lundvall 1992): Triple Helix model focuses on the organizational dimension of innovation system while institutional logics perspective is on the institutional dimension. The combination of the two provides a comprehensive understanding of the innovation system development in SEZs.

The paper takes Shenzhen SEZ as an example because it has shown some distinguished features and valuable experiences. As the first comprehensive Chinese SEZ established in 1980, Shenzhen has risen from a small town to a mega city in only three decades and provides a demonstration effect for China's reform. By 2007 Shenzhen's GDP had eclipsed by many times that of other SEZs and its economic output in per capita terms had dwarfed that of its competitors (Yeung et al. 2009). Shenzhen's high-tech industry performs even better than Chinese metropolitan cities such as Beijing, Guangzhou, Shanghai and Tianjin in both its value added and contribution to GDP (Y. Yuan et al. 2010). Thus, the Shenzhen case can be considered as the most successful SEZ in China and worth critical study. 
In the following, the paper will first elaborate a Triple Helix framework incorporating the institutional logics perspective to lay down the theoretical basis for the study. Then it will make an overview about the development of Shenzhen from the Triple Helix perspective and figure out its features. After that, it will explain the reasons and driving forces of Triple Helix model in Shenzhen from the institutional logics perspective. Finally, it will discuss the specialty of Triple Helix model in Shenzhen in comparison with other Chinese cities and regions.

\section{A Triple Helix framework incorporating the institutional logics perspective}

\subsection{Triple Helix}

Innovation system consists of complex functions and interactions among various organisations, including government, enterprises, universities and research institutes, as well as institutions in the forms of governmental policies and social norms (Edquist 1997; Lundvall 1992). Among a variety of approaches to studying innovation system (Martin 2008), Etzkowitz and Leydesdorff (1995) develop the concept of Triple Helix to explain the dynamic interactions between university, industry and government for fostering entrepreneurship, innovation and economic growth. The Triple Helix model, together with its extended variations such as the Quadruple Helix (Carayannis and Campbell 2009), Triple Helix Twins (Etzkowitz and Zhou 2006), as well as the new concept 'Triple Helix System' recently introduced by Ranga and Etzkowitz (2013), has commonly been used as a normative framework for understanding interactions between key actors in innovation processes.

Etzkowitz and Leydesdorff (2000) distinguish three types of Triple Helix models, namely the 'statist model', the 'laissez-fair model', and the 'balanced model' (Figure 1). In the statist model, government controls both academia and industry, and is expected to take the lead in developing projects and providing resources for new initiatives. In the laissez-faire model, industry, academia and government are separated from and independent of each other. These actors interact only 
modestly across strong boundaries. In the balanced Triple Helix, as an ideal model, the three spheres overlap and collaborate. 'The balanced configuration offers the most important insights for innovation, because the most favourable environments for innovation are created at the intersections of the spheres' (Ranga and Etzkowitz 2013: 239). The balanced model is considered an ideal Triple Helix, which begins from two opposing standpoints: the statist model and laissez-faire model (Etzkowitz 2008).

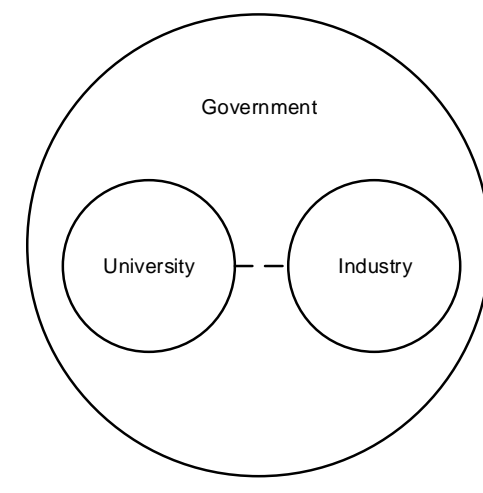

Statist model

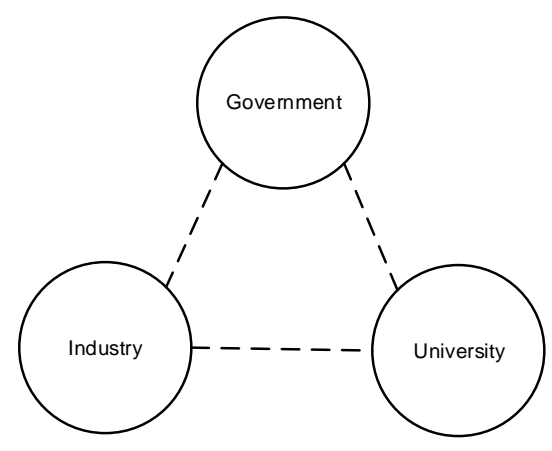

Laissez-faire model

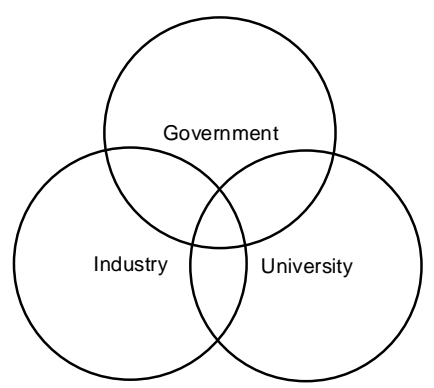

Balanced helix model

Figure 1. Three Triple Helix models

In addition to the three typical models of Triple Helix, some variations are also discussed in the literature. For instance, while the Triple Helix literature treats government as a single spiral in the Triple Helix interactions, Cai and Liu (2015) make distinction between central and local government in the Triple Helix framework. In their study on the role of university in the Triple Helix system in China, they found that governments at both central and local levels exerted significant though different influences on the shaping of Triple Helix system, and identified a delayed government-led model in the case of Tongji Creative Cluster (Figure 2). The delayed government-led model was initiated by the sectors of university and industry only, with the absence of government, then the local government was involved as a facilitator for university-industry interactions, and finally the central government took over the coordinative role and granted the cluster as an innovation exemplar at the national level. 


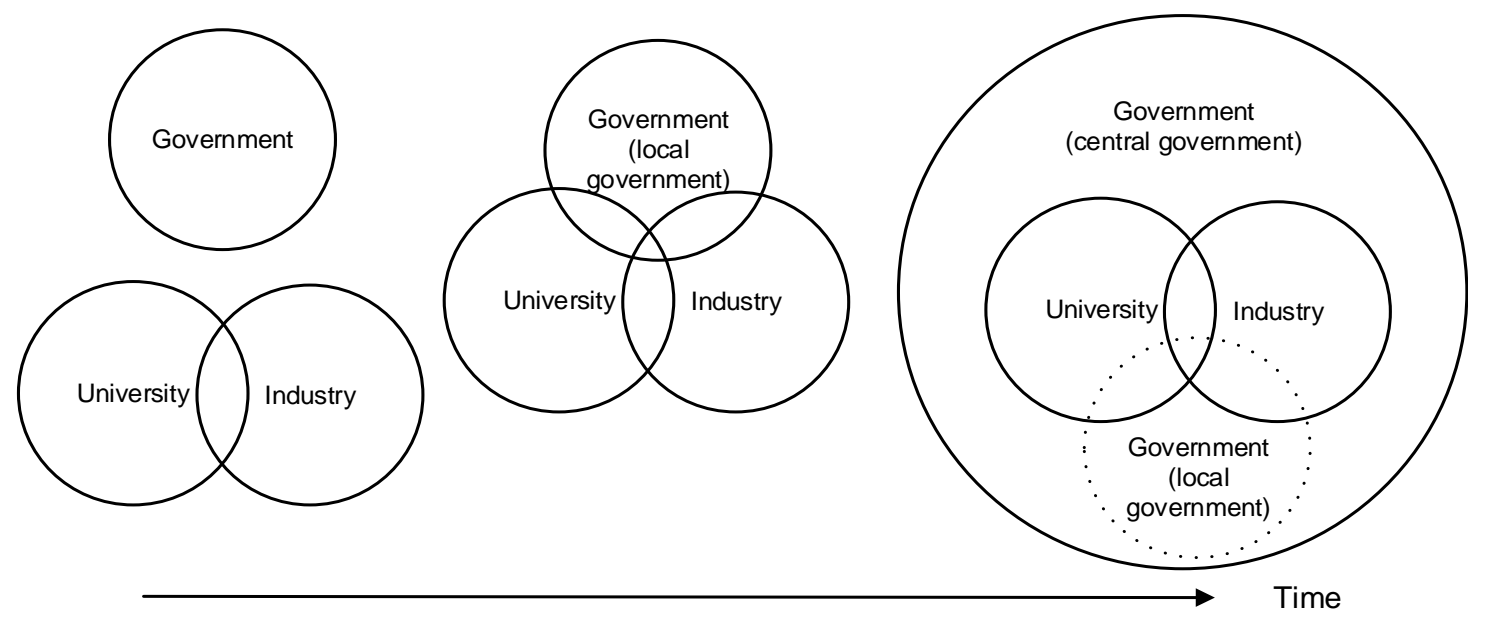

Figure 2. Delayed government-led model

\subsection{Incorporating the institutional logics perspective into Triple Helix framework}

The Triple Helix theories mainly seek to describe the generic features of the innovation model. It has been criticized for paying little attention to the national contexts (Balzat and Hanusch 2004; Shinn 2002: 610) and other social settings (Cooke 2005: 1130). Therefore the Triple Helix framework can hardly provide appropriate rationales on which systematically structured criteria and indicators can be developed for researching, measuring and comparing different empirical cases (Mowery and Sampat 2004), especially when the cases are in different national and cultural contexts (Eun et al. 2006). In such consideration, institutional theory (Greenwood et al. 2008), especially the institutional logics perspective (Thornton et al. 2012), may provide an explanatory tool to understand how the socio-cultural contexts affect innovation and Triple Helix system development (Cai 2015; Hollingsworth 2000).

Institutional logics are defined as the socially constructed patterns of symbols and material practices, assumptions, values, beliefs, and rules by which individuals and organizations produce and reproduce their material subsistence, organize time and space, and provide meaning to their social reality (Thornton and Ocasio 1999). The concept of institutional logics was originally used to account 
for institutional changes by Friedland and Alford (1991), who suggest that each society consists of a set of institutional orders and each of the institutional orders has a central institutional logic that constitutes its organising principles and is available to organisations and individuals for further elaboration. Drawing on the five institutional orders proposed by Friedland and Alford (1991), Thornton et al. (2012) extend them to seven, including family, religion, state, market, profession, corporation and community, which constitute the society into an inter-institutional system.

The institutional logics perspective was developed from the new institutional theory, sharing views with Meyer and Rowan (1977), Zucker (1977) and Dimaggio and Powell (1983) about how institutions shape organisational structures and constrain individual behaviours. But it also distinguishes from and transforms the new institutional theory in that its focus is no longer on institutional isomorphism but on the heterogeneity of institutions and how they comparatively vary by institutional orders (Thornton et al. 2012). One central pervasive argument of the institutional logics perspective is that multiple and contending logics provide the dynamic for potential change in both organisations and societies (Thornton et al. 2012). While institutional change may occur by replacing one dominant logic with another through competition, it can also be realised through collaboration mechanism that supports the co-existence of different logics (Reay and Hinings 2009; G. Zheng et al. 2017).

Applying the insights of institutional logics in Triple Helix, Cai $(2014,2015)$ treats the development of Triple Helix system as a process of institutionalisation and identifies seven institutional logics that are aligned with the institutionalisation of an ideal/balanced model of Triple Helix in western societies, namely 1) consensus on knowledge as the key to economic growth; 2) market orientation; 3) process-oriented knowledge management; 4) intellectual property rights protection; 5) civil society; 6) sense of competition for benefit; 7) democracy in policymaking. It is implied, though not explicitly, in the study of Cai $(2014,2015)$ that the seven institutional logics are respectively associated with the institutional orders of state, market, profession and community. For 
instance, the democratic policymaking is a central logic of the institutional order of state (in the Western context). The logics of market-oriented culture and competition for benefit mainly represent the institutional order of market. The consensus on technology innovation as the key to economic growth, process-oriented knowledge management and intellectual property protection assemble the institutional order of profession. The logic of civil society is fundamental of the institutional order of community.

\subsection{A renewed Triple Helix framework from the institutional logics perspective in the context of China}

All these logics discussed by Cai $(2014,2015)$ as well as the original discussion of institutional orders by Friedland and Alford (1991) and Thornton et al. (2012) refer to the western societies; their efficacy may vary in other social contexts. As the study of Cai $(2014,2015)$ shows that, although Chinese economic reforms have changed the policy environment in a direction that may facilitate the implementation of Triple Helix model in China, some institutional logics aligned with the Triple Helix activities in the West are largely absent in China, such as the logics of process management, civil society and democracy in policymaking.

While analysing the rationales of the special Triple Helix model in Shenzhen, this paper uses the category of institutional orders of state, market, and profession as general observation tools to identify the institutional changes. It uses institutional orders as guidelines because they are theoretically abstract and analytically distinct types which make it useful for studying multiple logics in conflict and consensus. It chooses the orders of state, market and profession because Chinese reforms and regional development is largely characterised by the counterbalance of state-market interaction (F. $\mathrm{Wu}$ et al. 2007) and because the innovation system development along with the rise of knowledge society has fundamentally changed professional logics in many fields (Powell and Snellman 2004). It doesn't take into consideration the institutional order of community as implied in the study of Cai $(2014,2015)$, because the civil society logics underlying the institutional order of community is rather 
weak in the context of China due to China's socialist regime, legislation framework, and traditional Chinese culture (B.-s. Tang et al. 2008).

In the following sections the paper will apply the renewed Triple Helix framework to explore the specialty of Triple Helix model in Shenzhen and the rationales of its specialty.

\section{The development of Shenzhen from the Triple Helix perspective}

\subsection{The first stage (1980-1983)}

When Shenzhen was designated by the central government as China's first SEZ in 1980, it was just a traditional fishing village. Such an undeveloped area was selected as the first bunch of SEZs because its financial contribution to the state was very little and thus any failure of the experiments would not jeopardise the state income and thus would not undermine the political authority in Beijing (Tian 1996). As one of the most significant steps of the reform, the central government decentralized the administrative power to local governments to approve investment projects within certain scale (Wong 1991). Thus it was possible to come up with a relatively favourable fiscal arrangement between the central and local governments, which allowed Shenzhen to retain a higher ratio of revenues for urban development.

At the initial stage, the focus of Shenzhen SEZ government was mainly on reforming the management of infrastructure construction and pricing, two systems that were heavily influenced by the planned economy and seriously restricted the SEZ development (Y. Yuan et al. 2010). It carried out a series of market-oriented measures in such fields as construction bidding, land market, commodity allocation, and labour contract. In particular, Shenzhen SEZ government established the industry economic management departments to promote industrial development according to economic needs and set up Shenzhen Foreign Exchange Centre to interact smoothly with foreign investors (Wei 2000). These measures broke the constraints of the planned economy and laid out the direction of reform clearly. 
With the ever-improving institutional framework, foreign investors began to come and played an important role for the initial development of Shenzhen. From 1980 to 1983, a total of 2.3 billion yuan was invested in fixed assets in Shenzhen, with overseas investors contributing more than onefourth (Shenzhen Statistics Bureau 2014). The industries of tourism and real estate development were more successful than others in attracting overseas capital. For example, in 1982, 67.8\% of FDI in Shenzhen went to tourism and real estate and only $16.3 \%$ to manufacturing industry (Wei 2000). In addition to the de facto needs of infrastructure development, this was also due to the shorter period of return and higher profit margins of investment in real estate and tourism (Wei 2000).

The development priority of infrastructure construction at the beginning stage was largely dependent on low-quality labours, therefore exerted little incentives on higher education. When Shenzhen was designated as SEZ in 1980, there was no university there at all. The universities in other areas of China were still governed as self-sufficient work units to serve the centrally-planned national economy; therefore it was impossible for them to undertake activities according to market needs in Shenzhen. The role of universities in promoting economic development was missing at the beginning stage.

At this stage, Triple Helix interaction was not fully established in Shenzhen (Figure 3). There was frequent interaction between local government and industry, which concentrated mainly in the fields of infrastructure construction. But neither of them interacted with the sector of university since there was neither local university in Shenzhen nor engagement of universities elsewhere. The central government was in charge of the approval, promotion and construction of Shenzhen and therefore took control of the interaction between local government and industry especially the foreign companies. 


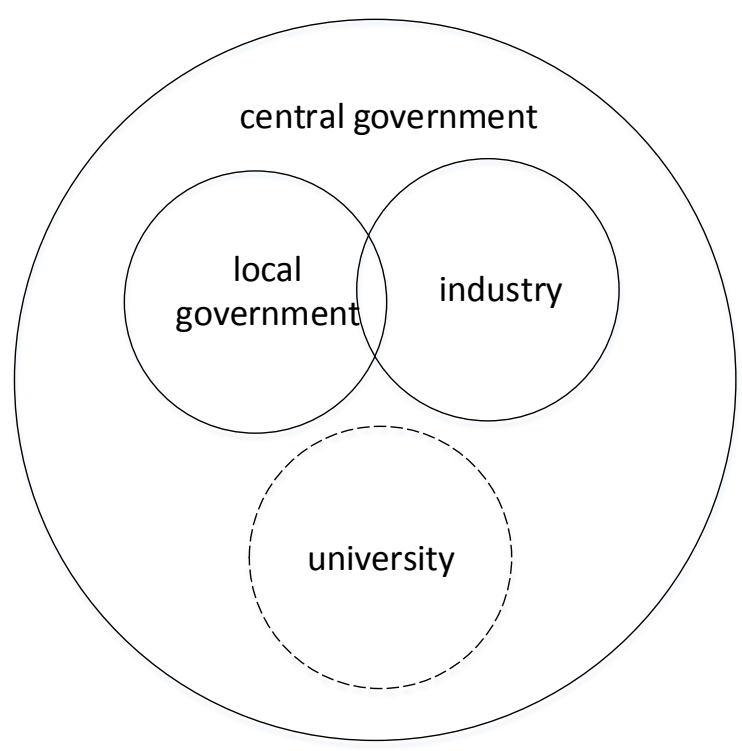

Figure 3. Triple Helix model of Shenzhen at the first stage

\subsection{The second stage (1983-1996)}

Along with the improvement of infrastructures, the development focus of Shenzhen was shifted to industrial development. To allow Shenzhen SEZ government more freedom in pursuing new polices and measures to vitalise the economy, the central government granted Shenzhen the same administrative power in economic development as a province in 1988 and empowered it the legislative authority in 1992 (Shen and Kee 2017). To channel the necessary technology and capital, the central government of China devised four flexible and practical forms of FDI participatory modes in 1986, i.e. joint venture, co-operation production, wholly foreign-owned companies, and other direct investment, and assigned different policies to different types of organizations.

An experiment of privatization was consequently initiated in Shenzhen. On the one hand, Shenzhen SEZ government privatized the state-owned enterprises and allowed them to make their own decision-making instead of following government instructions to make profit (Y. Yuan et al. 2010). On the other hand, Shenzhen SEZ government encouraged more private enterprises and foreign enterprises to run their own business according to their own strategies and market needs (Shen and Kee 2017). Given the inadequate supply of local technicians and technological facilities impeding 
the establishment of high-tech firms, Shenzhen SEZ government granted incentives to those labourintensive industries with an aim of transferring appropriate technology in accordance with the local needs and absorptive capability (Wei 2000).

At this stage, most FDI in Shenzhen concentrated in the manufacturing industries (Wei 2000). While foreign enterprises came to Shenzhen to reduce the cost of raw materials and labours and to enlarge the sales market, Shenzhen would like to collaborate with them for learning advanced technologies and management skills. It was estimated that $70 \%$ of the Chinese enterprises were technologically upgraded to various extents through collaboration with foreign enterprises (Lu 1993). They also gained knowledge and outlets of the international market. By 1998, Shenzhen accounted for $14 \%$ of world output of floppy disks, $6.2 \%$ of PC motherboards, $8 \%$ of hard disk drives and $10 \%$ in magnetic heads. Within the domestic market, it produced $70 \%$ of liquid crystal displays (LCDs), $33 \%$ of digital wireless telephones, $30 \%$ of personal computers and $85 \%$ of the floppy disks (Wei 2000).

To keep up with the fast economic development, Shenzhen SEZ government paid high attention to cultivating human capital. On the one hand, it set up the Labour Services Company to recruit candidate employees from other areas of China in order to maintain an adequate supply of cheap labours for the labour-intensive industries. On the other hand, it set up a local university, Shenzhen University, in 1983 to train professional manpower for local development. Before incorporating research as a development strategy in 2000 , Shenzhen University focused only on teaching and was incapable of building linkages with the industry for technology transfer. But its disciplinary structure was adjusted to align with the industrial structure and socio-economic needs of Shenzhen, with high emphasis on political economy, business administration, and computer science.

Triple Helix interactions in Shenzhen at this stage can be depicted in Figure 4. The sectors of local government and industry worked in close collaboration to promote SEZ development. The 
sector of university began emerging though weak mainly through cultivating human capital according to the guidelines of local government. There was nearly none direct interaction between university and industry because the research capability of local university was insufficient and the technological capability of labour-intensive industry was improved mainly through technology import and learning from foreign companies. Moreover, the central government still took control of SEZ development through devising institutional framework to guide local governance and FDI.

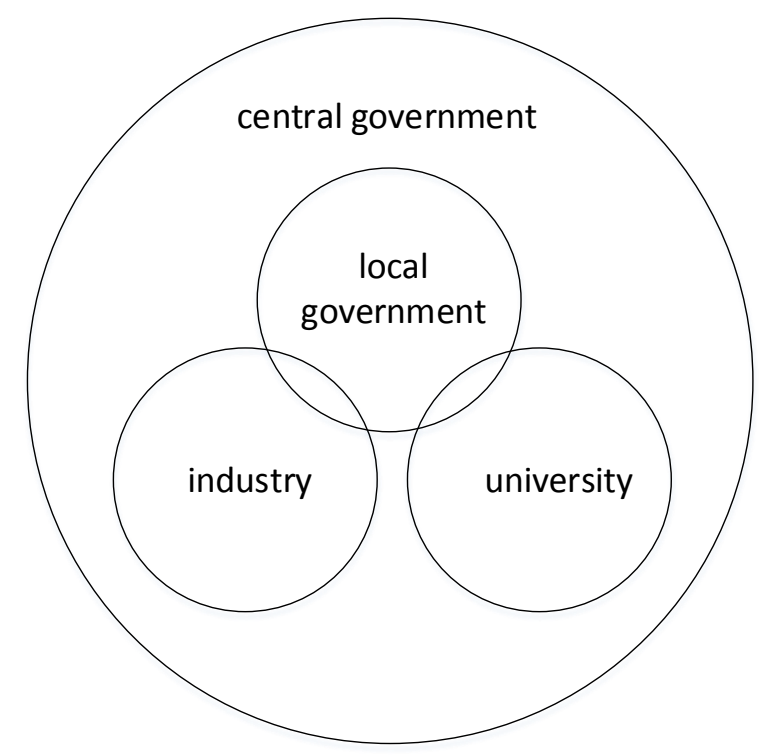

Figure 4. Triple Helix model of Shenzhen at the second stage

\subsection{The third stage (1996-now)}

When the experimentation of Shenzhen proved to be successful, the central government spread the special policies of SEZs to other regions of China. By 1992 all the provincial capital cities had adopted an openness approach to attracting FDI. Furthermore, the central government promoted China to join the World Trade Organisation (WTO) in 2001, which bounded all parts of the country to the same set of rules for liberalizing trade and opening to FDI (Yeung et al. 2009). At the same time, the competitiveness of Shenzhen was undermined by the rising land prices and labour cost (Wei 2000). In response to these challenges, Shenzhen SEZ government aimed to transform from labourintensive to technology-intensive development. 
In pursuit of this goal, Shenzhen SEZ government established the national-level Shenzhen HighTech Industrial Park (SHIP) in 1996 and then 16 municipal-level and 35 local-level parks (Cheng et al. 2014). It issued a number of policies such as Science and Technology Development Plan, Strategy of Science and Technology development, High and New Technology-Based Industries Development Plan to attract high-tech industries with strong capacity of innovation and research and development (R\&D). Moreover, Shenzhen SEZ government set up a series of offices, such as Quality Assurance Centre, Productivity Promotion Centre and Technology Market Centre, to provide services for technological development and enacted a series of laws and regulations for intellectual property protection (Wei 2000).

In the context of improving institutional framework, high-tech companies increased dramatically. In 1998, high-tech industry accounted for nearly $40 \%$ of the industrial output in Shenzhen (Wei 2000). In $2004,90 \%$ of the R\&D in Shenzhen was conducted by firms, and $80 \%$ of all R\&D funding originated from the industry (Cheng et al. 2014). At this stage, FDI still played an important role and $80 \%$ of enterprises in high-tech industries were joint ventures before 2000 (Wei 2000). However, the domestic high-tech industries began to rise. Many Chinese companies, such as Huawei, ZTE, and Great Wall headquartered in Shenzhen, invested heavily in R\&D and held large international market shares, especially in the field of telecommunication equipment (Yeung et al. 2009).

Along with the fast urban development, it was soon discovered that local universities were not sufficient and therefore Shenzhen SEZ government embarked to attract universities elsewhere. In 1996 it succeeded to convince Tsinghua University to establish research bases in SHIP, followed by four other universities and research institutes. In 2000, Shenzhen SEZ government promoted the concept of 'virtual campus' and attracted 58 universities and research institutes to locate branches as virtual campuses (Chen and Kenney 2007). Shortly after, it established Shenzhen University Town on the basis of the virtual campus, where three universities set up full-time graduate schools. 
The various universities have contributed greatly to the technology development and innovation in Shenzhen. In the virtual campuses, 15 technology-based incubators have incubated 1058 enterprises; the member institutes have taken 946 national-level technology projects, 187 projects at provincial level and 1119 projects at municipal level, with 994 patents and 1633 technology transfers (Shenzhen Virtual University Park 2017). Moreover, more than 25000 students have been graduated from Shenzhen University Town; 77 research labs and centres have been established at the municipal level and above. With the increasing intellectual resources, in 2011 Shenzhen SEZ government established a new local university, the Southern University of Science and Technology, with an aim of cultivating more talented people and experts and strengthening the city as a base for knowledge creation and innovation (Shen and Kee 2017).

At this stage, Triple Helix interactions evolved into an ideal model as shown in Figure 5. The central government loosened the control over Shenzhen while shifting the focus to other less developed regions and international affairs. The sectors of local government, industry and university built interactive linkages with each other. Local government created a favourable institutional environment to attract high-tech industries and universities elsewhere for local development. The industry, with emerging influences of domestic enterprises, conducted R\&D to upgrade their production and innovation capability. The universities engaged actively in technology transfer and the start-up of companies. The three sectors interacted with each other and took the role of the other. 


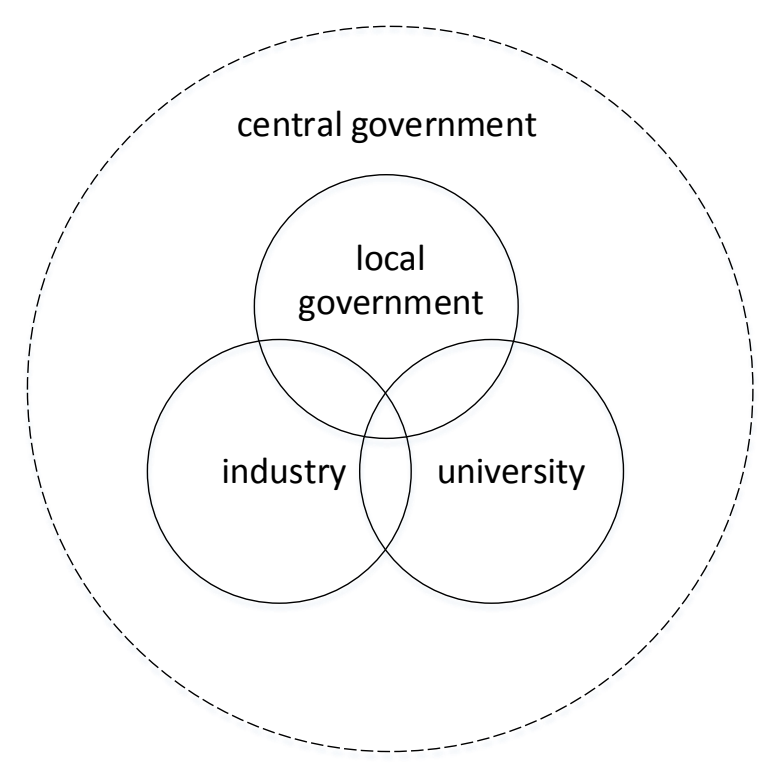

Figure 5. Triple Helix model of Shenzhen at the third stage

\subsection{The features of Triple Helix model in Shenzhen}

As elaborated above, the Triple Helix model in Shenzhen is characterised by the decreasing control of central government and the increasing balanced interaction of local government, industry and university. It can be defined as a statist-fading balanced model (Figure 6).

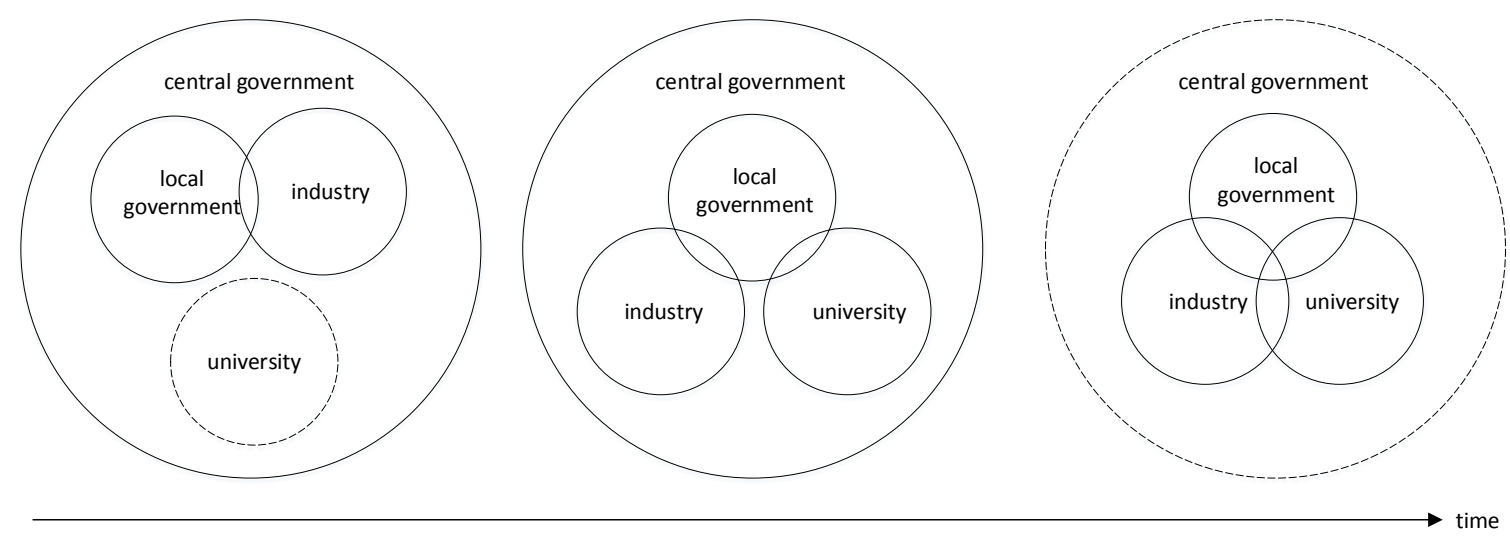

Figure 6. Statist-fading balanced Triple Helix model

In such a model, the central government initiated the reform process of Shenzhen and provided an efficient institutional framework to grant Shenzhen SEZ government the decentralized autonomy and development incentives. But along with the spread of reform policies from SEZs to the whole country and the increasing opening up of the whole country to the international market, the central 
government shifted its focus from the first batch of SEZs to other regions and loosened the control over Shenzhen.

Shenzhen SEZ government performed as mediator to formulate the development path and promote the engagement of industry and university. Originated from an inferior fishery village, Shenzhen was equipped with inadequate infrastructure and therefore the initial focus of Shenzhen SEZ government was on attracting FDI for infrastructure construction. Then it channelled FDI through lucrative incentives to the manufacturing industries for appropriate technology transfer, and finally targeted towards innovation and high-tech industries to improve the urban competitiveness. During the process, domestic industries learned advanced technologies through collaboration with foreign enterprises and held increasing shares in the domestic and international market.

Meanwhile, to meet the increasing intellectual requirement, Shenzhen SEZ government first established a local university and then attracted research universities elsewhere to the area through the initiatives of science parks, virtual campuses and university town. While the local university focused mainly on teaching and training, the various research universities built intensive linkages with the industry by setting up research labs, inventing patents, conducting technology transfer and incubating high-tech firms. The agglomeration of multiple universities transformed Shenzhen from a university barren to a university highland and boosted the innovation capability of Shenzhen.

\section{Driving forces of Triple Helix model in Shenzhen from the institutional logics perspective}

The statist-fading balanced model in Shenzhen takes on two distinct features: the fading of the central government in local governance and the balanced interaction of local government, industry and university. Forces driving the first feature are related to the internal changes of the state in 
rescaling the territories of governance, while the second feature is driven by the structural overlap of state, market and professional logics.

\subsection{Rescaling the state governance}

Inherited geographies of the state power have been fundamentally rescaled through the relationships on the subnational (cities or regions) and supranational (transnational) levels (Brenner 2004). In the case of Shenzhen, the loosened central control in local affairs and the rescaling of state governance can be explained from three aspects: the decentralization of state power, the disparity of regional economies, and the involvement in global networks.

As claimed by F. Wu (2002a), two central tasks for economic reform in China are: 1) to create new incentives at the sub-national level in order to increase efficiency production, and 2) to transfer the development pressure confronted by the central state to lower levels of the state apparatus. Fiscal reform effectively started the decentralisation of state power by redefining the financial responsibility of the central and local governments and allowing the latter increasing proportion of revenue (L. Y. Zhang 1999). In particular, Shenzhen was exempted from submitting tax revenues to the central and provincial governments over its first ten years as SEZ (Zhu 1996). This was an unparalleled advantage that allowed Shenzhen fundamental economic power to arrange investment and promote local growth. The additional administrative powers granted to Shenzhen, such as the legislative authority, further released the power of the central state and strengthened the legitimacy of Shenzhen localities in managing local development.

In fact, the SEZ experimentation is an unbalanced development strategy that grants some areas the development priority over others and promotes the concentration of resources there (Litwack and Qian 1998). It is consistent with the Chinese reform strategy, as stated by Deng Xiaoping, to let some areas get rich first. However, it easily exacerbates regional disparity, causing SEZs to advance at a greater rate than the other areas. The city-level data shows that in 1991 Shenzhen had the maximum 
per capita gross domestic product (PCGDP) in the country, which was over 45 times as large as the minimum PCGDP of Tongjiang in Heilongjiang Province (Song et al. 2000). In addition to the historical and geographical reasons, international trade and FDI based on the biased opening up policy of the central government are considered as the main driving forces behind the changes in regional disparity (Fujita and Hu 2001; W. Zhang 2001). To equalize regional development, to reduce social conflicts and to achieve the ultimate reform goals for common prosperity, the central government shifted the focus from the advanced SEZs to other undeveloped inland areas by spreading the opening up policies and providing significant financial support.

Meanwhile, the fast national economic progress, facilitated by its accession to WTO and the fragmentation of production, has propelled China to integrate quickly into global production networks. Between 1995 and 2006 the share of China in global manufacturing exports increased from $4 \%$ to $11 \%$. Its share in manufacturing of electrical equipment increased even more dramatically from $4 \%$ to $22 \%$ (Erumban et al. 2011). At the same time, China has become increasingly dependent on export for generating income and employment. Textiles, electrical machinery, manufacturing of furniture, sports goods and toy production depend for two-thirds or more of their income on foreign demand. Growth in exports provided almost 70 million jobs between 2001 and 2006 (Timmer et al. 2012), which absorbed millions of rural labours and contributed greatly to the Chinese urbanization process. The increasing involvement of China in the global production networks has a direct and tangible effect on the national affairs by all means and has enabled the state to rescale the governance with an international point of view.

\subsection{Structural overlap of state, market and professional logics}

Structural overlap is when individual roles and organizational structures and functions that were previously distinct are forced into association (Thornton 2004). The structural overlap of state, market and professional logics in the Triple Helix model of Shenzhen is set in the transition of China towards 
a market oriented economy and the rise of the knowledge society. The former process leads to the mixture of state and market logics in driving economic development, while the latter injects professional innovation incentives into economic agendas. These two trends have been closely intertwined in the Chinese context and enabled a set of common rules that local government, industry and university all adhere to.

Along with the retreat of the Chinese central state, local government has been trying to create a more favorable transactional environment to compete with other cities in attracting alternative sources such as foreign investors and private sectors for local economic development. This is especially the case for Shenzhen since all SEZs are designated with clear goals in GDP growth, exports, employment, revenues, FDI generation and the like (Zeng, 2010). Such competition and development pressure is further intensified by the government and party structures in China because in a nonelected government system, leaders are judged for promotion according to the development success of their current localities ( $\mathrm{Gu}$ and Tang, 2002). This constitutes the local dimension of place promotion in Shenzhen and makes the local government become a developmental state to legitimize and facilitate market operation (He and $\mathrm{Wu} 2009)$.

While lacking original innovation and core technology, Shenzhen SEZ government adopted a unique learning model to make the role of imported technology and knowledge from foreign companies for economic development (Wei 2000). Innovation was aimed to be achieved through introducing foreign technology and knowledge, then understanding and mastering them, and finally fostering high-level technological capability on its own (Y. Wang and Lu 2014; X. Wu 2002b; Xu et al. 1998). It is in fact a strategy of 'using (domestic) market to obtain (foreign) technology' (F. Wu 2009), coupling the regional assets (such as cheap labour, land and geographical proximity) with needs of global production networks (such as cost-down and time-to-market) through conducive institutions (Yang 2012). 
In 2008 innovation policies in Shenzhen was shifted towards indigenous innovation explicitly through state-led coupling of designated domestic firms and leading foreign firms (Yang 2014). While foreign enterprises still hold a large share in the urban economy of Shenzhen, representing over $50 \%$ of the industrial output value in 2013 (Shenzhen Municipal Statistics Bureau 2014), a group of private enterprises, such as Huawei, ZTE, Tencent and BYD, have been cultivated with independent innovation capabilities. Altogether, the domestic private and foreign enterprises become the pillars of Shenzhen's economy. The pro-growth government and aggressive enterprises have formed a close public-private coalition with regard to urban development (Zhu 1999). The development of Shekou Industrial Zone and Overseas Chinese Town clearly revealed the pioneering inter-dependent relationship and close collaboration between local government and enterprises (Shen and Kee 2017).

While enterprises are put at the centre of innovation, they are encouraged to operate in collaboration with university (S. Gu et al. 2009). The increasing engagement of universities, especially the cross-city engagement of universities elsewhere in Shenzhen, is deeply influenced by the Chinese higher education reform. Broader economic reforms in China have led to the conscious retreat of the state from being the sole provider of higher education (Hawkins 2000; Mok 1997, 2000). Therefore since 1985 China has put forward a series of reforms in higher education to eliminate excessive government control over universities and to strengthen their ties with industries. Under such guidelines, universities attempt to market their academic wares in the commercial world and at the same time to restructure themselves in terms of business principles and practices (Buchbinder and Newson 1990). Typical measures include cultivating research universities, promoting universityindustry linkages, developing university-run enterprises, establishing science parks and managing multi-campus system (Liu 2017).

Among these measures, the multi-campus system is most distinct because it marks the transformation of university from single institution to system of institutions (Creswell et al. 1985). In 
1999 the cross-city multi-campus system of university was legalized in China. Correspondingly, universities began to shift locations between cities purposely to build up new core markets. The gap between supply and demand of higher education resources in Shenzhen (K. Zhang and Fan 2013) and the importance of geographical proximity for innovation (Boschma 2005; Chaminade and Nielsen 2011; Mattes 2012) have led to the ultimate set up of cross-city branch campuses of many competitive research universities in Shenzhen. All of these universities are affiliated to the Ministry of Education and have the same administrative power as Shenzhen SEZ government at the vice-ministry/viceprovincial level. Therefore they perform as an equal partner rather than simply follower of local government when participating in economic development.

During the reform process of China from a centrally planned economy towards a market oriented economy and incorporating innovation as a momentum for economic growth, local government, industry and university all get development incentives and form into alliances. A key point worth attention is the dependence of Shenzhen on external resources, i.e. the major competitive enterprises and universities were both introduced from outside Shenzhen. They are not only competitive enough to perform as the main actor of innovation, but also not politically affiliated to and thus not controlled by local government. This is an important factor leading to their equal status and balanced interaction.

\section{The specialty of Shenzhen}

The development path of Shenzhen along with the evolution of statist-fading balanced model differentiates a lot from other Chinese cities and regions. The other cities/regions can be classified into three categories in comparison with Shenzhen. The first type is non-SEZ cities. The second type is SEZ cities, especially those in the same batch of SEZs as Shenzhen. The third type is cities with smaller scale areas designated as SEZs, typically those economically successful cities such as Shanghai. 
Comparing with the first type of cities, the specialty of Shenzhen is mainly represented in its unique temporal advantages and early bird benefits in reform and opening up. Whereas in the early years Shenzhen was 'special' by virtue of the exclusive policies and privileges, it is now no longer the only window in China for exploring new socio-economic policies and attracting FDI. Moreover, based on the experiences of Shenzhen, some cities perform even better in structural transformation and technological learning. For example, Hangzhou has developed an incremental co-governance model involving government, enterprises and grass-root non-governmental organizations for sustainable urban innovation (M. Wang and Liu 2017). However, what cannot be replicated in other cities is the accumulative effect of the temporal parameters in Shenzhen. In particular, some intangible capital, such as the entrepreneurial culture, institutional milieu and human capital, is formed through cumulative growth over a long period of time (Becker 1993) and is deeply rooted in action and in a specific context (Nonaka 1991) which cannot be easily transferrable to other areas.

In comparison with other SEZs such as Zhuhai, Shantou, Xiamen and Hainan, the specialty of Shenzhen is mainly due to its geographical proximity to and symbiotic relationship with Hong Kong. As all the SEZs are adjacent to China's borders, the prospects of their integration with the more advanced neighbouring areas have been a major concern since their designation. Among the first batch of SEZs, Zhuhai share boundaries with Macao, but their cross-boundary cooperation has not yielded visible results due to the limited spill-over effect of the predominating gambling industry in Macao (U. W. Tang and Sheng 2009) and the suppressed industrialization in Zhuhai for ecological considerations (Sheng and Tang 2013). Shantou and Xiamen are opposite to Taiwan across the strait. The political stalemate in Taiwan does not allow the two cities to implement in any tangible way the specific regional roles envisioned for their discharge (Yeung et al. 2009). Hainan is an independent island and does not have any advanced neighbouring city to rely on; therefore it is difficult to achieve successful urban transformation from an agricultural economy to an industrial economy. In contrast, Shenzhen and Hong Kong has integrated economically, socially and physically over the past decades, 
which is of complementary advantages and mutual benefit for both sides to develop as a crossboundary metropolis (Yang 2005).

With regard to the third type of cities, taking Shanghai as an example, the special features of Shenzhen are represented in three aspects. First, the central-local relations are looser in Shenzhen than in Shanghai. Shanghai has always played a strategic role in China as the cradle of the national industry and as a significant source of state revenues (F. R. Gu and Tang 2002), whereas Shenzhen used to be an unimportant fishery village. Therefore Shenzhen was designated as a comprehensive SEZ for reform and experimentation while SEZs in Shanghai were established much later and piece by piece to avoid the risks of undermining the national economy. Along with the fast urban development in both cities, Shanghai was elevated as a provincial level city while Shenzhen as a viceprovincial level city listed separately in the national socio-economic plan. This means Shenzhen SEZ government has the administrative power at the provincial level only in terms of economic development and without any other authorities except its legislative power granted in 1992. Therefore some important leaders such as President Jiang Zemin and Premier Zhu Rongji serving in the central government of China rose to prominence in connection to the Shanghai municipal administration rather than Shenzhen, which contributes to the prevailing of local experiences and values of Shanghai in the central government.

Second, the local government was more powerful to coordinate industrial development in Shanghai than in Shenzhen. Stemming from its historical legacy, the economic growth in Shanghai has been dominated by state-owned enterprises through upgrading the traditional manufacturing industries with advanced technologies. In contrast, Shenzhen has been driven by FDI for economic growth and paid high value to the development of new information and communication technologies (Guo and Wei 2007). The different modes of industrial development in the two cities are both the cause and effect of the strategic arrangements of the local government. Shanghai municipal government adopted a strategy of 'high input, high risk and a high level of reliance on government 
guidance' in its industrial growth and provided more information, procurement and funds to the enterprises, whereas Shenzhen SEZ government preferred a laissez-faire attitude and advocates a free economy without much state intervention (C. C. Wang 2013).

Third, there have been a stronger higher education and research system in Shanghai than in Shenzhen. Shenzhen established the first local university in 1983 and introduced several other universities in the next decades. As of 2013, there were ten higher education institutes in Shenzhen and trained 18618 graduates (Shenzhen Municipal Statistics Bureau 2014). In the same year, Shanghai had 68 higher education institutes, some of which were established over a century ago, and trained 133800 graduates (Shanghai Municipal Statistics Bureau 2014). The well-established higher education system in Shanghai has laid down solid basis to support and accelerate the process of technological innovation (C. C. Wang 2013). During the national wave of redistributing higher education resources and incorporating them for innovation in the recent years, especially through the set-up of cross-city branch campuses, Shenzhen is a major importing city while Shanghai is exporting, which may perform as a new incentive to leverage the innovation capacity of the two cities.

Due to the different roles of government, industry and university, the Triple Helix models of Shanghai and Shenzhen also differentiate a lot. As studied by Cai and Liu (2015), the innovation initiatives in (some areas of) Shanghai can be launched spontaneously by university and industry on the basis of their traditional connections and strong competitiveness, with little government intervention, but they were ultimately under the state control when their socio-economic effects showed up. In contrast, although the government, especially the central government, participated actively in the initial development of Shenzhen, it finally took a hands-off approach to let local government, industry and university interact with each other in an equal way. Such a statist-fading balanced model in Shenzhen proceeds in a quite opposite way as the delayed government-led model in Shanghai. 


\section{Conclusion}

The statist-fading balanced model in Shenzhen is characterised by the decreasing control of central government and the increasing balanced interaction between local government, industry and university. It is quite different from the Chinese statist model in which government pulls the other two spheres (Etzkowitz et al. 2007) or the delayed government-led model in which the central government takes an increasing role in mediating the interactions between local government, university and industry (Cai and Liu 2015). Several lessons can be learned from Shenzhen for innovation system development:

First, it's important to combine top-down policies with bottom-up initiatives. As designated by the central government, Shenzhen SEZ was originated from top-down initiatives. A top-down approach is practically useful because it provides an effective institutional framework through favourable policies and priorities granted by central government. However, the bottom-up initiative is equally necessary because it's more open to all the possibilities and provokes incentives and engagement of various actors, especially the local government, industry and university. The integration of top-down and bottom-up initiatives in Shenzhen enables all the actors to engage actively in the innovation system development.

Second, more important is to keep balance between top-down and bottom-up initiatives. Although the intervention of central government was indispensable to cope with the complex functions and diverse interaction among various organizational and institutional factors, it gradually retreated to grant the locality more autonomy and facilitate a vibrant environment for local development. The Shenzhen case presents the functional mechanism mediating between top-down and bottom-up initiatives in response to specific needs of different development stages.

Third, external resources are valuable supplement to indigenous innovation. Indigenous innovation capability in Shenzhen is developed through technological learning from foreign 
companies. It also relies heavily on universities elsewhere for cultivating human capital and transferring technology. This is all the more efficient than developing indigenous innovation capability from scratch. Moreover, the administrative autonomy of industry and university from other places is critical for them to function as equal partner of Shenzhen SEZ government rather than simply policy followers.

Fourth, forces driving the Triple Helix model in Shenzhen are embedded in certain institutional logics, which cannot be easily transferred to other places. The loosened central control in Shenzhen is attributed to the internal changes of state logics, i.e. the rescaling of state governance due to the decentralization of state power, the disparity of regional economies, and the involvement in global networks, whereas the interaction of local government, industry and university is driven by the structural overlap of state, market and professional logics along with the transition of China towards a market oriented economy and the rise of the knowledge society. Although some aspects of these changing logics can also be perceived in other Chinese cities, none of them are undergoing such comprehensive and dramatic changes as Shenzhen. Moreover, the temporal and geographical advantages of Shenzhen as well as some special features of innovation actors, such as laissez-faire governance, dependence on FDI and weaker higher education tradition, contribute to the specialty of Shenzhen in developing such a special Triple Helix model.

\section{References}

Balzat, Markus and Hanusch, Horst (2004), 'Recent trends in the research on national innovation systems', Journal of Evolutionary Economics, 14 (2), 197-210.

Becker, G. S. (1993), Human Capital: A Theoretical and Empirical Analysis (3rd Edition edn.; Chicago: The University of Chicago Press).

Boschma, Ron (2005), 'Proximity and Innovation: A Critical Assessment', Regional Studies, 39 (1), 61-74.

Brenner, Neil (2004), New State Spaces: Urban Governance \& the Rescaling of Statehood (New York: Oxford University Press). 
Buchbinder, Howard and Newson, Janice (1990), 'Corporate-university linkages in Canada: Transforming a public institution', Higher Education, 20 (4), 355-79.

Cai, Yuzhuo (2014), 'Implementing the Triple Helix model in a non-Western context: an institutional logics perspective', Triple Helix, 1 (1), 1-20.

--- (2015), 'What contextual factors shape 'innovation in innovation'? Integration of insights from the Triple Helix and the institutional logics perspective', Social Science Information, 54 (3).

Cai, Yuzhuo and Liu, Cui (2015), 'The Roles of Universities in Fostering KnowledgeIntensive Clusters in Chinese Regional Innovation Systems', Science \& Public Policy, 42 (1).

Carayannis, Elias G. and Campbell, David F. J. (2009), "Mode 3" and "Quadruple Helix": Toward a 21st century fractal innovation ecosystem', International journal of technology management = Journal international de la gestion technologique, 46 (3/4), 20134(34).

Chaminade, Cristina and Nielsen, Hjalti (2011), 'Transnational innovation systems', Eclac.

Chen, Kun and Kenney, Martin (2007), 'Universities/Research Institutes and Regional Innovation Systems: The Cases of Beijing and Shenzhen', World Development, 35 (6), 105674.

Cheng, Fangfang, et al. (2014), 'Science parks and the co-location of high-tech smalland medium-sized firms in China's Shenzhen', Urban Studies, 51 (5), 1073-89.

Cooke, Phil (2005), 'Regionally asymmetric knowledge capabilities and open innovation: Exploring 'Globalisation 2'-A new model of industry organisation', Research Policy, 34 (8), 1128-49.

Creswell, J. W., Roskens, R. W., and Henry, T. C. (1985), 'A Typology of Multicampus Systems', Journal of Higher Education, 56 (1), 26-37.

Dimaggio, Paul J and Powell, Walter W (1983), 'The iron cage revisited: Institutional isomorphism and collective rationality', American Sociological Review, 42 (2), 147-60.

Ding, Daniel, Fields, Dail, and Akhtar, Syed (1997), 'An empirical study of human resource management policies and practices in foreign-invested enterprises in China: the case of Shenzen Special Economic Zone', International Journal of Human Resource Management, volume 8 (5), 595-613.

Easterby-Smith, M., Araujo, L. , and Burgoyne, J. G. (1999), Organizational Learning and Learning Organization: Developments in Theory and Practice (London: Sage).

Edquist, Charles (ed.), (1997), Systems of innovation: technologies, institutions and organizations (London: Printer).

Erumban, Abdul Azeez, et al. (2011), 'Making Room for China: a Global Value Chain Approach', DIME Final Conference (Maastricht).

Etzkowitz, Henry (2008), The Triple Helix: University-industry-government innovation in action (New York ; London: Routledge).

Etzkowitz, Henry and Leydesdorff, Loet (1995), 'The Triple Helix--University-IndustryGovernment Relations: A Laboratory for Knowledge-Based Economic Development', Glycoconjugate Journal, 42 (2), 14--19. 
--- (2000), 'The dynamics of innovation: from National Systems and "Mode 2" to a Triple Helix of university-industry-government relations', Research Policy, 29 (2), 109-23.

Etzkowitz, Henry and Zhou, Chunyan (2006), 'Triple Helix twins: innovation and sustainability', Journal of Northeastern University, 33 (1), 77-83.

Etzkowitz, Henry, et al. (2007), 'University-Industry-Government Interaction: the Triple Helix Model for Innovation', Asia Pacific Tech Monitor, 24 (1), 14-23.

Eun, Jong Hak, Lee, Keun, and Wu, Guisheng (2006), 'Explaining the "University-run enterprises" in China: A theoretical framework for university-industry relationship in developing countries and its application to China $\aleph^{2}$ ', Research Policy, 35 (9), 1329-46.

Friedland, Roger and Alford, Robert R. (1991), 'Bringing society back in: Symbols, practices, and institutional contradictions', in Walter W Powell and Paul J Dimaggio (eds.), The New Institutionalism in Organizational Analysis (Chicago: University of Chicago Press), 232-63.

Fujita, Masahisa and Hu, Dapeng (2001), 'Regional disparity in China 1985-1994: The effects of globalization and economic liberalization', The Annals of Regional Science, 35 (1), 3-37.

Ge, Wei (1999), 'Special Economic Zones and the Opening of the Chinese Economy: Some Lessons for Economic Liberalization', World Development, 27 (7), 1267-85.

Greenwood, Royston, et al. (2008), 'Introduction', in Royston Greenwood, et al. (eds.), The SAGE handbook of organizational institutionalism (Los Angeles ; London: SAGE), 146.

Gu, F. R. and Tang, Z. (2002), 'Shanghai: Reconnecting to the global economy', in S. Sassen (ed.), Global networks, linked cities (New York: Routledge).

$\mathrm{Gu}$, Shulin, et al. (2009), 'China's System and Vision of Innovation: An Analysis in Relation to the Strategic Adjustment and the Medium- to Long-Term S\&T Development Plan (2006-20)', Industry \& Innovation, 16 (4-5), 369-88.

Guo, Shiping and Wei, Zhihao (2007), 'A Comparative Analysis of Technology Innovation Policies amorng Beijing, Shanghai and Shenzhen', Journal of Hunan Business College, 14 (1), 57-59.

Hawkins, John N. (2000), 'Centralization, decentralization, recentralization: educational reform in China', Journal of Educational Administration, 38 (5), 442-55.

He, Shenjing and Wu, Fulong (2009), 'China's Emerging Neoliberal Urbanism: Perspectives from Urban Redevelopment', Antipode, 41 (2), 282-304.

Heilmann, Sebastian (2008), 'Policy Experimentation in China's Economic Rise', Studies in Comparative International Development, 43 (1), 1-26.

Hollingsworth, J. Rogers (2000), 'Doing institutional analysis: implications for the study of innovations', Review of International Political Economy, 7 (4), 595-644.

Litwack, John M and Qian, Yingyi (1998), 'Balanced or Unbalanced Development: Special Economic Zones as Catalysts for Transition', Journal of Comparative Economics, 26 (1), 117-41.

Liu, Cui (2017), University spatial development and urban transformation in China (London and New York: Routledge). 
Lu, Ping (1993), Guangdong Economic Construction and Science \& Technology Development (Guangdong Science and Technology Press).

Lundvall, Bengt-Åke (ed.), (1992), National systems of innovation : towards a theory of innovation and interactive learning (London, New York: Pinter Publishers) xiii, 342 p.

Martin, Ben R. (2008), 'The evolution of science policy and innovation studies', Research Policy, 41 (7), 1219-39.

Mattes, Jannika (2012), 'Dimensions of Proximity and Knowledge Bases: Innovation between Spatial and Non-spatial Factors', Regional Studies, 46 (8), 1085-99.

Meyer, John W. and Rowan, Brian (1977), 'Institutionalized Organizations: Formal Structure as Myth and Ceremony', American Journal of Sociology, 83 (2), 340-63.

Mok, Ka Ho (1997), 'Privatization or marketization: Educational development in postMao China', International Review of Education, 43 (5-6), 547-67.

--- (2000), 'Marketizing higher education in post-Mao China', International Journal of Educational Development, 20 (2), 109-26.

Mowery, David C. and Sampat, Bhaven N. (2004), 'Universities in National Innovation Systems', in J. Fagerberg, D. C. Mowery, and R. R. Nelson (eds.), Oxford Handbook of Innovation (Oxford: Oxford University Press), 209-39. 96-104.

Nonaka, I. (1991), 'The knowledge-creating company', Harvard Business Review, 69 (6),

Powell, Walter W. and Snellman, Kaisa (2004), 'The knowledge economy', Annual Review of Sociology, 30 (1), 199-220.

Ranga, Marina and Etzkowitz, Henry (2013), 'Triple Helix Systems: An Analytical Framework for Innovation Policy and Practice in the Knowledge Society. , 27(4), Special Issue (August 2013).', Industry and Higher Education, 27 (4), 237-62.

Reay, Trish and Hinings, C. R. (2009), 'Managing the Rivalry of Competing Institutional Logics', Organization Studies, 30 (6), 629-52.

Shanghai Municipal Statistics Bureau (2014), Shanghai Statistical Yearbook.

Shen, Jianfa and Kee, Gordon (2017), 'Shenzhen: Innovation and Governments' Roles in Reform and Development', Development and Planning in Seven Major Coastal Cities in Southern and Eastern China (Springer), 61-92.

Sheng, N. and Tang, U. W. (2013), 'Zhuhai', Cities, 32 (4), 70-79.

Shenzhen Municipal Statistics Bureau (2014), Shenzhen Statistical Yearbook.

Shenzhen Statistics Bureau (2014), Shenzhen Statistics Yearbook.

Shenzhen Virtual University Park <http://www.szvup.com/Html/xygk/3840.html〉, accessed May 2, 2017.

Shinn, Terry (2002), 'The Triple Helix and New Production of Knowledge: Prepackaged Thinking on Science and Technology', Social Studies of Science, 32 (4), 599-614.

Song, Shunfeng, Chu, George S.-F., and Cao, Rongqing (2000), 'Intercity regional disparity in China', China Economic Review, 11, 246-61. 
Tang, Bo-sin, Wong, Siu-wai, and Lau, Milton Chi-hong (2008), 'Social impact assessment and public participation in China: A case study of land requisition in Guangzhou', Environmental Impact Assessment Review, 28 (1), 57-72.

Tang, U. W. and Sheng, N. (2009), 'Macao', Cities, 26 (4), 220-31.

Tantri, Malini L. (2012), 'China's Policy for Special Economic Zone Some Critical Issues', India Quarterly A Journal of International Affairs, 68 (68), 231-50.

The State Council of China (1996), 'Decision on Concerning the Deepening of the Reform of the Science and Technology Management System During the "Ninth Five-year Plan" Period '.

Thornton, Patricia H. (2004), Markets from Culture: Institutional Logics and Organizational Decisions in Higher Education Publishing (Stanford: Stanford University Press).

Thornton, Patricia H. and Ocasio, William (1999), 'Institutional Logics and the Historical Contingency of Power in Organizations: Executive Succession in the Higher Education Publishing Industry, 1958 - 1990', American Journal of Sociology, 105 (3), 801-43.

Thornton, Patricia H., Ocasio, William, and Lounsbury, Michael (2012), The institutional logics perspective : a new approach to culture, structure and process (Oxford University Press).

Tian, Gang (1996), Shanghai's role in the economic development of China (Praeger).

Timmer, Marcel, Los, Bart, and Vries, Gaaitzen J. De (2012), 'China and the World Economy: A Global Value Chain Perspective on Exports, Incomes and Jobs', GGDC Research Memorandum.

Wang, Cassandra C (2013), Upgrading China's information and communication technology industry (World Scientific; Zhejiang University Press).

Wang, Ming and Liu, Guohan (2017), Incremental Co-governance: Investigation of Hangzhou Experience of Driving Reform Through Innovation, ed. Ming Wang (A Discussion on Chinese Road of NGOs: Reform and Co-governance by Society; Singapore: Springer).

Wang, Yongdong and Lu, Liejin (2014), 'Export-oriented economy as moderator of the relationship between technology acquisition model and independent innovation', International Conference on Information Management, Innovation Management and Industrial Engineering, 34-37.

Wei, Xie (2000), 'Acquisition of technological capability through special economic zones (SEZs): The case of Shenzhen SEZ', Industry \& Innovation, 7 (7), 199-221.

Wong, Christine P. W. (1991), 'Central-Local Relations in an Era of Fiscal Decline: The Paradox of Fiscal Decentralization in Post-Mao China', China Quarterly, 128 (128), 691-715.

Wu, Fulong (2002a), 'China's Changing Urban Governance in the Transition towards a More Market-Oriented Economy', Urban Studies, 39 (7), 1071-93.

--- (2009), 'Globalization, the changing state, and local governance in Shanghai', in X. Chen and Z. Zhou (eds.), Shanghai rising: State power and local transformations in a global megacity (Minneapolis and London: University of Minnesota Press).

Wu, Fulong, Xu, Jiang, and Yeh, Anthony G. O. (2007), Urban development in postreform China: State, market, and space (Oxon and New York: Routledge) 1295-97. 
Wu, Weiping (2007), 'State Policies, Enterprise Dynamism, and Innovation System in Shanghai, China', Growth and Change, 38 (4), 544-66.

Wu, Xiaobo (2002b), 'The evolutionary process of secondary innovation', Innovation in Technology Management - The Key to Global Leadership. PICMET '97: Portland International Conference on Management and Technology, 183.

Xu, Q.R., Chen, J., and Guo, B. (1998), 'Perspective of Technological Innovation and Technology Management in China', IEEE Transactions on Engineering Management, 45 (4), 381-87.

Xue, Lan (2006), 'Universities in China's National Innovation System', The UNESCO Forum on Higher Education, Research and Knowledge.

Yang, Chun (2005), 'An emerging cross-boundary metropolis in China: Hong Kong and Shenzhen under 'Two Systems", International Development Planning Review, 27 (2), 195225.

--- (2012), 'Restructuring the export-oriented industrialization in the Pearl River Delta, China: Institutional evolution and emerging tension', Applied Geography, 32 (1), 143-57.

--- (2014), 'State-led technological innovation of domestic firms in Shenzhen, China: Evidence from liquid crystal display (LCD) industry', Cities, 38 (38), 1-10.

Yeung, Yueman , Lee, Joanna , and Kee, Gordon (2009), 'China's Special Economic Zones at 30', Post-Soviet Geography and Economics, 50 (2), 222-40.

Yuan, Shengjun and Zhao, Xiangzhong (2011), 'A Study on Government Role in the Formation Process of Industrial Belt around University: Based on the Analysis of 'Tongji Phenomenon", Science \& Technology Progress \& Policy, 28 (19), 57-60.

Yuan, Yiming, et al. (2010), 'China's First Special Economic Zone: The Case of Shenzhen', in Douglas Zhihua Zeng (ed.), Building engines for growth and competitiveness in China (World Bank), 55-86.

Zeng, Douglas Zhihua (2010), 'How Do Special Economic Zones and Industrial Clusters Drive China's Rapid Development?', in Douglas Zhihua Zeng (ed.), Building engines for growth and competitiveness in China (World Bank), 1-53.

Zhang, Kai and Fan, Kun (2013), 'On the Innovational Capabilities of the Special Economic Zones of China', Studies on China's Special Economic Zones, 6 (1), 35.

Zhang, Le Yin (1999), 'Chinese Central-provincial Fiscal Relationships, Budgetary Decline and the Impact of the 1994 Fiscal Reform: An Evaluation*', China Quarterly, 157 (157), 115-41.

Zhang, Wei (2001), 'Rethinking Regional Disparity in China', Economic Change and Restructuring, 34 (1), 113-38.

Zheng, Gaoming, Cai, Yuzhuo, and Ma, Shaozhuang (2017), 'Towards an analytical framework for understanding the development of a quality assurance system in an international joint programme', European Journal of Higher Education, 1-18.

Zheng, Yuxing and Cao, Yong (1993), 'The Impact of Economic Reform on Productivity Growth in Chinese Industry: A Case of Xiamen Special Economic Zone', Asian Economic Journal, 7 (2), 107-46.

Zhu, Jieming (1996), 'Denationalization of urban physical development', Cities, 13 (3), 187-94. 
--- (1999), 'Local Growth Coalition: The Context and Implications of China's Gradualist Urban Land Reforms', International Journal of Urban and Regional Research, 23 (3), 53448 .

Zucker, Lynne G. (1977), 'The Role of Institutionalization in Cultural Persistence', American Sociological Review, 42 (5), 726-43. 